\title{
Outcomes of surgical aortic valve replacement over three decades
}

\author{
Mevlüt Çelik, MD, Andras P. Durko, MD, Jos A. Bekkers, MD, PhD, Frans B. S. Oei, MD, PhD, \\ Edris A. F. Mahtab, MD, PhD, and Ad J. J. C. Bogers, MD, PhD
}

\section{ABSTRACT}

Objective: The study objective was to analyze temporal changes in baseline and procedural characteristics and long-term survival of patients undergoing surgical aortic valve replacement over a 30-year period.

Methods: A retrospective analysis of patients undergoing surgical aortic valve replacement between 1987 and 2016 in the Erasmus Medical Center (Rotterdam, The Netherlands) was conducted. Patient baseline and procedural characteristics were analyzed in periods according to the date of surgical aortic valve replacement (period A: 1987-1996; B: 1997-2006; C: 2007-2016). Survival status was determined using the Dutch National Death Registry. Relative survival was obtained by comparing the survival after surgical aortic valve replacement with the survival of the age-, sex-, and year-matched general population.

Results: Between 1987 and 2016, 4404 patients underwent SAVR. From period A to $C$, the mean age increased from $63.9 \pm 11.2$ years to $66.2 \pm 12.3$ years $(P<.001)$, and the prevalence of diabetes mellitus, hypertension, hypercholesterolemia, previous myocardial infarction, and previous stroke at baseline increased ( $P$ values for trend for all <.001). The prevalence of concomitant procedures increased from $42.4 \%$ in period $A$ to $48.3 \%$ in period $C(P=.004)$. Bioprosthesis use increased significantly (18.8\% in period A vs $67.1 \%$ in period $C, P<.001$ ). Mean survival after surgical aortic valve replacement was 13.8 years. Relative survival at 20 years in the overall cohort was $60.4 \%$ (95\% confidence interval, $55.9-65.2)$ and $73.8 \%$ (95\% confidence interval, 67.1-81.1) in patients undergoing isolated primary surgical aortic valve replacement.

Conclusions: Patient complexity has been continuously increasing over the last 30 years, yet long-term survival after surgical aortic valve replacement remains high compared with the age-, sex-, and year-matched general population. (J Thorac Cardiovasc Surg 2022;164:1742-51)

Invasive treatment of aortic valve disease has been continuously evolving since the first surgical aortic valve replacement (SAVR) was performed in the 1960s. ${ }^{1}$ Technical and procedural refinements, continuous prosthesis development, and periprocedural care improvement resulted in a substantial improvement of SAVR outcomes over the last

\footnotetext{
From the Department of Cardiothoracic Surgery, Erasmus University Medical Center, Rotterdam, The Netherlands.

Received for publication July 25, 2020; revisions received April 9, 2021; accepted for publication April 12, 2021; available ahead of print April 28, 2021.

Address for reprints: Edris A. F. Mahtab, MD, PhD, Department of Cardiothoracic Surgery, Erasmus Medical Center, PO Box 2040, 3000 CA Rotterdam, The Netherlands (E-mail: e.mahtab@erasmusmc.nl).

0022-5223

(C) 2021 The Authors. Published by Elsevier Inc. on behalf of The American Association for Thoracic Surgery. This is an open access article under the CC BY license (http://creativecommons.org/licenses/by/4.0/).

https://doi.org/10.1016/j.jtcvs.2021.04.064
}

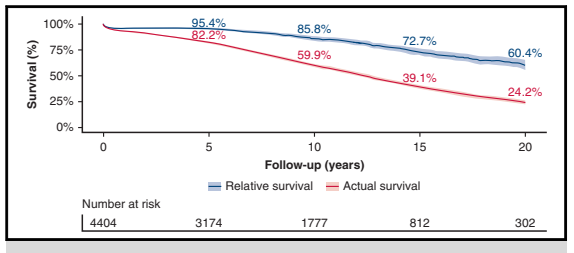

Long-term actual and relative survival after SAVR.

CENTRAL MESSAGE

In a large SAVR cohort, relative survival is close to $90 \%$ at 10 years. This excellent long-term result reinforces the role of SAVR, especially in younger lowrisk patients with long life expectancy.

\section{PERSPECTIVE}

These excellent long-term results, especially in the younger low-risk patient population with long life expectancy and lower operative risk, reinforce the role of SAVR in the treatment of aortic valve disease and serve as a benchmark for future dedicated long-term TAVR studies.

See Commentaries on pages 1752 and 1753 . decades. ${ }^{2}$ Concurrently, patient characteristics have changed considerably, and the comorbidity burden is increasing. ${ }^{2,3}$

The latest revolution in treating aortic valve replacement was the introduction of transcatheter aortic valve replacement (TAVR) in the early 2000s. ${ }^{4}$ Attractive for its less invasiveness, TAVR quickly became an established treatment modality for patients with aortic stenosis (AS) having high or intermediate surgical risk. ${ }^{5,6}$ More recently, clinical trial results have even challenged the role of SAVR in low-

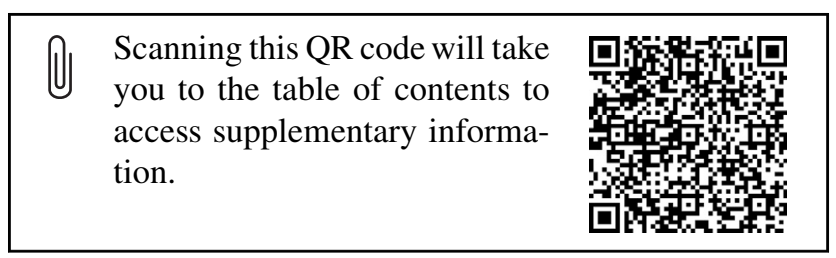




\section{Abbreviations and Acronyms \\ AS $=$ aortic stenosis \\ $\mathrm{CABG}=$ coronary artery bypass grafting \\ $\mathrm{CI}=$ confidence interval \\ LVEF $=$ left ventricular ejection fraction \\ SAVR $=$ surgical aortic valve replacement \\ TAVR $=$ transcatheter aortic valve replacement}

risk patients with $\mathrm{AS}^{7,8}$ These results forecast a new era in treating aortic valvular pathology, when optimal treatment allocation will become increasingly important.

Detailed analysis of patient and procedural characteristics, especially long-term survival after SAVR, is inevitable for informed treatment decisions. This study aimed to assess the trends in patient and procedural characteristics and the long-term survival in SAVR in a high-volume tertiary center over the last 3 decades.

\section{MATERIALS AND METHODS \\ Study Design and Data Collection}

Adult patients undergoing SAVR between 1987 and 2016 at the Erasmus Medical Center, Rotterdam, The Netherlands, were analyzed. Patients receiving bioprosthetic or mechanical aortic valve prosthesis with or without concomitant cardiac procedures were included. Patients aged less than 18 years and patients receiving valved conduits were excluded. Baseline and procedural characteristics were collected retrospectively from electronic medical records. Survival status was obtained through the Dutch National Death Registry.

This study was conducted according to the privacy policy of the Erasmus Medical Center and regulations for the appropriate use of data in patient-oriented research, which are based on international regulations, including the Declaration of Helsinki (Institutional MEC Number: MEC2019-0721), and patient informed consent was waived. All the authors vouch for the validity of the data and adherence to the protocol.

\section{End Points and Definitions}

The primary end point was the differences in baseline and procedural characteristics in the overall and primary isolated SAVR cohort, in three 10-year time periods according to the date of SAVR (period A: 19871996; B: 1997-2006; C: 2007-2016). The survival in the overall and primary isolated SAVR cohort was analyzed and compared with the survival of the matched general population (relative survival). SAVR within 24 hours of establishing the indication was classified as urgent. SAVR after 24 hours was classified as (semi-) elective. Left ventricular function was classified as normal if the left ventricular ejection fraction (LVEF) was greater than $50 \%$, as reduced if the LVEF was $30 \%$ to $50 \%$, and as severely reduced if the LVEF was less than $30 \%$, as measured or estimated by a trained echocardiographer. Low-, intermediate-, and high-risk patients are defined as logistic European System for Cardiac Operative Risk Evaluation of 10 or less, 10 to 20 , and 20 or greater, respectively.

\section{Statistical Analysis}

Categorical variables are presented as numbers, percentages, or proportions and compared with the chi-square test or the Fisher exact test, where appropriate. Continuous variables are presented as means \pm standard deviation or median with the interquartile range and compared with the 2sample $t$ test or Wilcoxon rank-sum test where appropriate. Patients were classified into 10-year time periods based on surgery date (period A: 1987-1996; period B: 1997-2006; period C: 2007-2016). Trend analysis was performed with the chi-square test for trend.

The relative survival can be used as an estimate of cause-specific mortality. It is defined as the ratio between the observed survival and the expected survival in the general population. ${ }^{9}$ The Human Mortality Database was used to obtain the age-, sex-, and year-matched expected survival data of the general population of The Netherlands. ${ }^{10}$ The Human Mortality Database is continuously updated and includes mortality data from the Netherlands up until 2016. Relative survival is estimated through the Ederer II method. ${ }^{11,12}$ Data management and statistical analyses were performed using SPSS 25.0 (SPSS Inc, Chicago, Ill) and R software, version 3.5 (R Foundation, Vienna, Austria).

\section{RESULTS}

\section{Baseline Characteristics}

Between 1987 and 2016, a total of 4404 patients underwent SAVR with a biological $(\mathrm{n}=2301)$ or mechanical $(\mathrm{n}=2103)$ valve prosthesis. No patients were lost to follow-up for survival, with a mean follow-up of 13.8 years. Mean age was $65.5 \pm 12.1$ years, and $38.2 \%(\mathrm{n}=1683)$ were female. A total of $46.3 \%(\mathrm{n}=2041)$ required concomitant procedures, and $5.6 \%(\mathrm{n}=247)$ had redo SAVR. The indication for operation was AS or combined AS and aortic regurgitation in most cases $(83.9 \%)$. The most common comorbidities included hypertension $(35.1 \%, \mathrm{n}=1545)$, atrial fibrillation $(17.6 \%, \mathrm{n}=775)$, and diabetes mellitus $(14.9 \%, \mathrm{n}=656)$. The median logistic European System for Cardiac Operative Risk Evaluation (available since $2003 ; \mathrm{n}=2605)$ was $5.0 \%$, with $18.8 \%(\mathrm{n}=480)$ of the patients having a logistic European System for Cardiac Operative Risk Evaluation of $10 \%$ or greater and $6.0 \%$ $(\mathrm{n}=153)$ having a logistic European System for Cardiac Operative Risk Evaluation of $20 \%$ or greater. Further baseline characteristics are shown in Table 1 for the overall cohort and in Tables E1 and E2 for the isolated SAVR and the SAVR with concomitant CABG cohort.

\section{Changes in Patient Profile Over Three Decades}

wDuring the 30-year observation period, the annual number of patients undergoing SAVR per period increased, from an annual average of 91 in period $\mathrm{A}$ to 187 in period $C$ (Figure 1). The mean age increased from $63.9 \pm 11.2$ years in period A to $66.2 \pm 12.3$ years in period $\mathrm{C}(P<.001)$. The proportion of patients aged 70 years or more increased from $35.2 \%$ in period $\mathrm{A}$ to $46.7 \%$ in period $\mathrm{C}$ $(P<.001)$. Between periods $\mathrm{A}$ and $\mathrm{C}$, the prevalence of diabetes mellitus in the study population increased from $7.6 \%$ to $20.5 \%(P<.001)$, hypercholesterolemia from $5.2 \%$ to $25.0 \%(P<.001)$, and chronic obstructive pulmonary disease from $7.9 \%$ to $12.1 \%(P<.001)$. The percentage of patients with previous cardiac operations $(P<.001)$ and redo SAVR decreased $(P=.023)$. Further changes in baseline characteristics are shown in Table 1 for the overall cohort and in Tables $\mathrm{E} 1$ and E2 for the primary isolated SAVR and the primary SAVR with concomitant CABG cohort. 
TABLE 1. Baseline characteristics over three decades in the overall cohort

\begin{tabular}{|c|c|c|c|c|c|}
\hline & $\begin{array}{l}\text { All patients } \\
(n=4404)\end{array}$ & $\begin{array}{c}\text { Period A 1987-1996 } \\
\quad(n=911)\end{array}$ & $\begin{array}{c}\text { Period B 1997-2006 } \\
\quad(n=1627)\end{array}$ & $\begin{array}{c}\text { Period C 2007-2016 } \\
(n=1866)\end{array}$ & $\begin{array}{c}\text { Chi-square } \\
P \text { value } \\
\end{array}$ \\
\hline Age at operation, y (mean \pm SD) & $65.5 \pm 12.1$ & $63.9 \pm 11.2$ & $65.5 \pm 12.3$ & $66.2 \pm 12.3$ & $<.001$ \\
\hline$<40$ & $180(4.1)$ & $33(3.6)$ & $67(4.1)$ & $80(4.3)$ & .427 \\
\hline $40-49$ & $302(6.8)$ & $74(8.1)$ & $121(7.4)$ & $107(5.6)$ & .006 \\
\hline $50-59$ & $649(14.7)$ & $157(17.2)$ & $239(14.7)$ & $253(13.6)$ & .013 \\
\hline $60-69$ & $1330(30.2)$ & $326(35.8)$ & $448(27.5)$ & $556(29.8)$ & .012 \\
\hline $70-79$ & $1641(37.3)$ & $297(32.6)$ & $641(39.4)$ & $703(37.7)$ & .041 \\
\hline$\geq 80$ & $303(6.9)$ & $24(2.6)$ & $111(6.8)$ & $168(9.0)$ & $<.001$ \\
\hline Female & $1683(38.2)$ & $338(37.1)$ & $679(41.7)$ & $666(35.7)$ & .134 \\
\hline \multicolumn{6}{|l|}{ Indication $(n=4370)$} \\
\hline AS & $2894(66.2)$ & $499(55.4)$ & $1086(66.9)$ & $1309(70.9)$ & $<.001$ \\
\hline $\mathrm{AR}$ & $771(17.6)$ & $163(18.1)$ & $277(17.1)$ & $331(17.9)$ & .966 \\
\hline Combined AS + AR & $705(16.1)$ & $239(26.5)$ & $260(16.0)$ & $206(11.2)$ & $<.001$ \\
\hline Bicuspid aortic valve & $697(15.8)$ & $234(25.7)$ & $255(15.7)$ & $208(11.2)$ & $<.001$ \\
\hline Endocarditis & $292(6.6)$ & $67(7.4)$ & $95(5.8)$ & $130(7.0)$ & .983 \\
\hline $\begin{array}{l}\text { Logistic euroSCORE } \\
\qquad(\mathrm{n}=2073)(\text { median, IQR) }\end{array}$ & $5.0(2.9-8.4)$ & N/A & $5.0(2.7-8.1)$ & $5.1(2.9-8.4)$ & .188 \\
\hline$\geq 10$ & $480(18.8)$ & & $127(18.4)$ & $353(18.9)$ & .772 \\
\hline$\geq 20$ & $153(6.0)$ & & $36(5.2)$ & $117(6.3)$ & .320 \\
\hline Previous cardiac operation & $553(12.6)$ & $146(16.0)$ & $200(12.3)$ & $207(11.1)$ & $<.001$ \\
\hline SAVR & $247(5.6)$ & $74(8.1)$ & $72(4.4)$ & $101(5.4)$ & .023 \\
\hline Creatinine $\geq 2 \mathrm{mg} / \mathrm{dL}$ & $132(3.0)$ & $25(2.7)$ & $36(2.2)$ & $71(3.8)$ & .020 \\
\hline Previous hemodialysis & $32(0.7)$ & $5(0.5)$ & $10(0.6)$ & $17(0.9)$ & .240 \\
\hline Atrial fibrillation & 775 (17.6) & $160(17.6)$ & $258(15.9)$ & $357(19.1)$ & .134 \\
\hline Diabetes mellitus & $656(14.9)$ & $69(7.6)$ & 205 (12.6) & $382(20.5)$ & $<.001$ \\
\hline Cardiac decompensation & $728(16.5)$ & $210(23.1)$ & $259(15.9)$ & $259(13.9)$ & $<.001$ \\
\hline Hypertension & $1545(35.1)$ & $186(20.4)$ & $456(28.0)$ & $903(48.4)$ & $<.001$ \\
\hline Hypercholesterolemia & $720(16.3)$ & $47(5.2)$ & 207 (12.7) & $466(25.0)$ & $<.001$ \\
\hline Previous myocardial infarction & $507(11.5)$ & $92(10.1)$ & $178(10.9)$ & $237(12.7)$ & .030 \\
\hline Previous PCI & $306(6.9)$ & $27(3.0)$ & $82(5.0)$ & 197 (10.6) & $<.001$ \\
\hline COPD & $455(10.3)$ & $72(7.9)$ & $157(9.6)$ & $226(12.1)$ & $<.001$ \\
\hline History of cancer & $314(7.1)$ & $27(3.0)$ & $111(6.8)$ & $176(9.4)$ & $<.001$ \\
\hline History of stroke & $398(9.0)$ & $45(4.9)$ & $132(8.1)$ & $221(11.8)$ & $<.001$ \\
\hline Arterial disease & $195(4.4)$ & $21(2.3)$ & $59(3.6)$ & $115(6.2)$ & $<.001$ \\
\hline Peripheral & $170(3.9)$ & $20(2.2)$ & $51(3.1)$ & $99(5.3)$ & $<.001$ \\
\hline Carotid & $32(0.7)$ & $1(0.1)$ & $12(0.7)$ & $19(1.0)$ & .010 \\
\hline \multicolumn{6}{|l|}{$\operatorname{LVEF}(n=4026)$} \\
\hline Good & $3147(78.2)$ & $577(77.4)$ & $1185(79.3)$ & $1385(77.5)$ & .771 \\
\hline Reduced & $729(18.1)$ & $120(16.1)$ & $264(17.7)$ & $345(19.3)$ & .046 \\
\hline Severely reduced & $150(3.3)$ & $48(6.4)$ & $46(3.1)$ & $56(3.1)$ & .001 \\
\hline
\end{tabular}

Values are presented as n (\%) or as mean \pm SD or median (interquartile range) if otherwise stated. $S D$, Standard deviation; $A S$, aortic stenosis; $A R$, aortic regurgitation; euro$S C O R E$, European System for Cardiac Operative Risk Evaluation; $I Q R$, interquartile range; N/A, not available; SAVR, surgical aortic valve replacement; $P C I$, percutaneous coronary intervention; $C O P D$, chronic obstructive pulmonary disease; $L V E F$, left ventricular ejection function.

\section{Trends in Procedural Characteristics and Prosthesis Use}

During the study period, $46.3 \%(\mathrm{n}=2041)$ of the SAVR patients underwent concomitant procedures (Table 2), with a significant increase from $42.4 \%$ in period $A$ to $48.3 \%$ in period $\mathrm{C}(P=.004)$. Most commonly, concomitant CABG was performed $(\mathrm{n}=1433,32.5 \%)$. Among patients undergoing concomitant CABG, $41.2 \%(\mathrm{n}=590)$ had singlevessel disease and $58.8 \%(\mathrm{n}=843)$ had multiple-vessel disease. The proportion of patients requiring concomitant CABG for single-vessel disease remained constant during the 30-year observation period $(P=.412)$. Patients with 


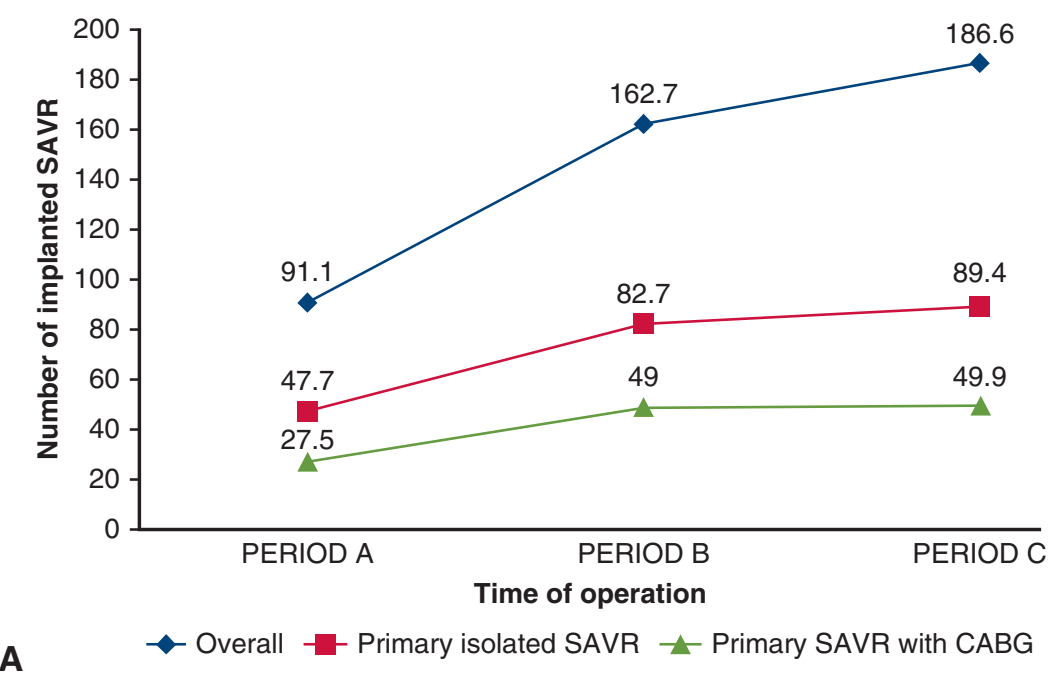

A

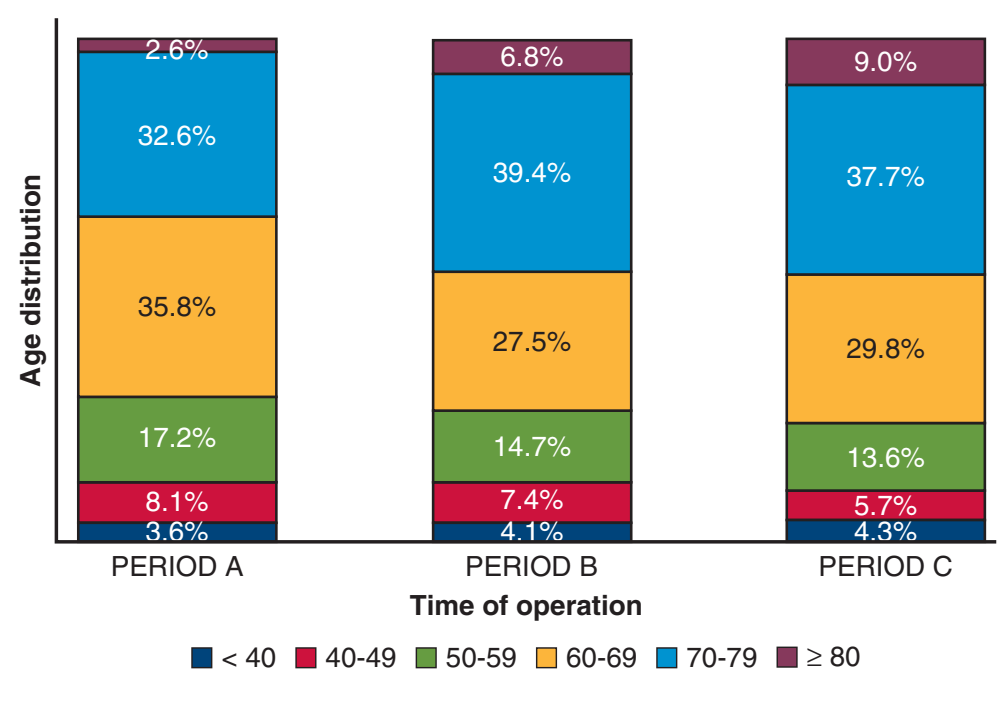

FIGURE 1. Age at operation and annual number of patients undergoing SAVR over 30 years. Over 30 years, the percentage of elderly patients and the annual number of patients undergoing SAVR increased considerably. Results are reported according to the time of SAVR (period A: 1987-1996; B: 1997-2006; C: 2007-2016). A, Annual average of patients undergoing SAVR, according to the type of surgery. $Y$-axis represents the absolute number of patients. B, Age distribution of patients at the time of SAVR. SAVR, Surgical aortic valve replacement; $C A B G$, coronary artery bypass grafting.

concomitant $\mathrm{CABG}$ were older compared with patients not requiring revascularization $(70.1 \pm 8.3$ vs $65.0 \pm 12.0$; $P<.001$ ). From period A to period $\mathrm{C}$, the incidence of concomitant tricuspid and aortic procedures increased. The proportion of patients receiving bioprosthetic valves increased significantly, from $18.8 \%$ in period A to $67.1 \%$ in period $\mathrm{C}(P<.001$, Figure 2$)$. Detailed trends regarding changes in procedural characteristics and concomitant procedures are provided in Table 2 .

\section{Trends in 30-Day Mortality and Long-Term Survival}

The 30-day mortality in the overall cohort decreased from $2.7 \%$ in period $\mathrm{A}$ to $1.8 \%$ in period $\mathrm{C}(P=.003)$. The 30-day mortality across 3 decades decreased, nonsignificantly, from $1.9 \%$ to $0.9 \%(P=.190)$ for primary isolated SAVR, and from $4.1 \%$ to $3.0 \%(P=.384)$ for primary SAVR with CABG (Table E3). The 10-year survival was $59.8 \%$ in the overall cohort, $65.5 \%$ in the isolated SAVR cohort, and $51.1 \%$ in the SAVR with concomitant CABG group (Table 3).

From period A to C, 10-year survival did not change in the overall cohort and patients receiving isolated SAVR from $62.8 \%$ to $60.3 \%(P=.051)$ and $66.9 \%$ to $67.2 \%$, respectively (Table 3). Further trends in 10 -year survival in various subgroups are displayed in Table 3 and Figures E1 to E3. Further trends in survival are shown in Tables E4 and E5.

\section{Relative Survival}

In the overall cohort, relative survival at $1,5,10$, and 20 years was $95.7 \%$ (confidence interval [CI], 95.0-96.5), 
TABLE 2. Procedural characteristics over three decades in the overall cohort

\begin{tabular}{|c|c|c|c|c|c|}
\hline & $\begin{array}{c}\text { All patients } \\
(n=4404)\end{array}$ & $\begin{array}{l}\text { Period A 1987-1996 } \\
\quad(n=911)\end{array}$ & $\begin{array}{l}\text { Period B 1997-2006 } \\
\quad(n=1627) \\
\end{array}$ & $\begin{array}{c}\text { Period C 2007-2016 } \\
(\mathrm{n}=\mathbf{1 8 6 6})\end{array}$ & $\begin{array}{c}\text { Chi-square } \\
P \text { value } \\
\end{array}$ \\
\hline $\begin{array}{l}\text { Urgency }(\mathrm{n}=3763) \\
\quad(\text { Semi-)elective }(>24 \mathrm{~h}) \\
\text { Urgent }(<24 \mathrm{~h})\end{array}$ & $\begin{array}{c}98.0 \\
2.0\end{array}$ & $\begin{array}{c}97.6 \\
2.4\end{array}$ & $\begin{array}{c}98.0 \\
2.0\end{array}$ & $\begin{array}{c}98.0 \\
2.0\end{array}$ & .640 \\
\hline Concomitant cardiac procedure & 46.3 & 42.4 & 46.3 & 48.3 & .004 \\
\hline CABG & 32.5 & 32.8 & 34.0 & 31.1 & .226 \\
\hline $1 \mathrm{VD}$ & 41.2 & 45.2 & 39.1 & 41.1 & .412 \\
\hline $2 \mathrm{VD}$ & 29.2 & 30.4 & 30.0 & 27.7 & .362 \\
\hline $3 \mathrm{VD}$ & 29.7 & 24.4 & 30.9 & 31.2 & .060 \\
\hline MV procedure & 10.5 & 10.0 & 10.4 & 10.9 & .465 \\
\hline TV procedure & 2.6 & 1.0 & 2.1 & 3.8 & $<.001$ \\
\hline $\mathrm{MV}$ and TV procedure & 1.8 & 0.9 & 1.5 & 2.6 & .001 \\
\hline Ascending aorta/arch replacement & 3.0 & 0.3 & 2.6 & 4.5 & $<.001$ \\
\hline Prosthesis type & & & & & $<.001$ \\
\hline Mechanical & 47.8 & 81.2 & 46.1 & 32.9 & \\
\hline Biological & 52.2 & 18.8 & 53.9 & 67.1 & \\
\hline Prosthesis size & $23.6 \pm 2.4$ & $23.9 \pm 2.2$ & $23.7 \pm 2.5$ & $23.3 \pm 2.3$ & $<.001$ \\
\hline 19 & 3.9 & 1.6 & 3.0 & 5.8 & $<.001$ \\
\hline 21 & 22.6 & 19.3 & 21.8 & 24.9 & .001 \\
\hline 23 & 32.7 & 34.3 & 31.6 & 32.9 & .630 \\
\hline 25 & 24.9 & 28.1 & 24.2 & 23.9 & .029 \\
\hline 27 & 12.1 & 12.6 & 13.2 & 10.9 & .106 \\
\hline 29 & 3.5 & 3.6 & 5.8 & 1.4 & $<.001$ \\
\hline
\end{tabular}

Values are presented as percentages. $C A B G$, Coronary artery bypass grafting; $V D$, vessel disease; $M V$, mitral valve; $T V$, tricuspid valve.

95.4\% (CI, 94.1-96.8), 85.8\% (CI, 83.5-88.1), and 60.4\% (CI, 55.9-65.2), respectively (Figure 3). In the cohort undergoing primary isolated SAVR, the relative survival was 98.1\% (CI, 97.3-99.0), 99.9\% (CI, 98.3-101.6), 92.4\% (CI, 89.4-95.6), and 73.8\% (CI, 67.1-81.1) at 1, 5, 10, and 20 years, respectively (Figure 4). In patients undergoing primary SAVR with $\mathrm{CABG}$, the relative survival was 94.8\% (CI, 93.2-96.4), 94.3\% (95\% CI, 91.6-97.3), $83.4 \%$ (95\% CI, $78.5-88.4)$, and $41.6 \%$ (95\% CI, 33.452.0 ), at 1, 5, 10, and 20 years, respectively (Figure 5). Long-term actual and relative survivals in the overall cohort are shown in Figure 6.

\section{DISCUSSION}

In this study, although the age, frequency of comorbid conditions, and complexity of patients undergoing SAVR increased over a 30-year period, the trends in 10-year survival remained stable or improved. Relative survival after SAVR was $85.8 \%$ (CI, 83.5-88.1) at 10 years. In patients undergoing primary isolated SAVR, the relative survival was $92.4 \%$ (CI, 89.4-95.6) and $73.8 \%$ (CI, 67.1-81.1) at 10 and 20 years, respectively. These excellent long-term results reinforce the role of SAVR in the treatment of aortic valve disease, especially in the younger low-risk patient population with long life expectancy and lower operative risk.
In our cohort, we saw a continuous increase in the number of patients undergoing SAVR. This increase is parallel to the growing number of SAVRs performed annually in Europe and the United States over the last decades, ${ }^{13}$ and is most likely a result of a combination of factors. The ageing of the population led to an increase in the prevalence of AS in the Western countries, ${ }^{14,15}$ and improvements in imaging might have led to an increase of patients being referred for SAVR. ${ }^{16}$ Simultaneously, expanding indications for SAVR and practice-related changes had a positive effect on the number of SAVRs performed. ${ }^{5,17}$ Of note, this trend might be halted by the growing use of TAVR in elderly patients, which can eventually lead to a decrease in the annual number of SAVRs, a recent trend already observed in some countries. ${ }^{18,19}$

The increasing frequency of comorbidities in our patient population is in accordance with the previously described changes in the profile of patients undergoing cardiac surgery. ${ }^{20}$ The prevalence of diabetes mellitus, hypercholesterolemia, and hypertension has at least doubled during the 30year observation period. Diabetes is associated with worse outcomes in patients undergoing cardiac surgery. ${ }^{21}$ Further, $31.1 \%$ of the patients in this study underwent concomitant CABG. Hypercholesterolemia and hypertension are well known to be associated with coronary artery disease. Coronary artery disease is present in up to $40 \%$ of the patients with AS undergoing SAVR and in up to $50 \%$ in SAVR 
Period A

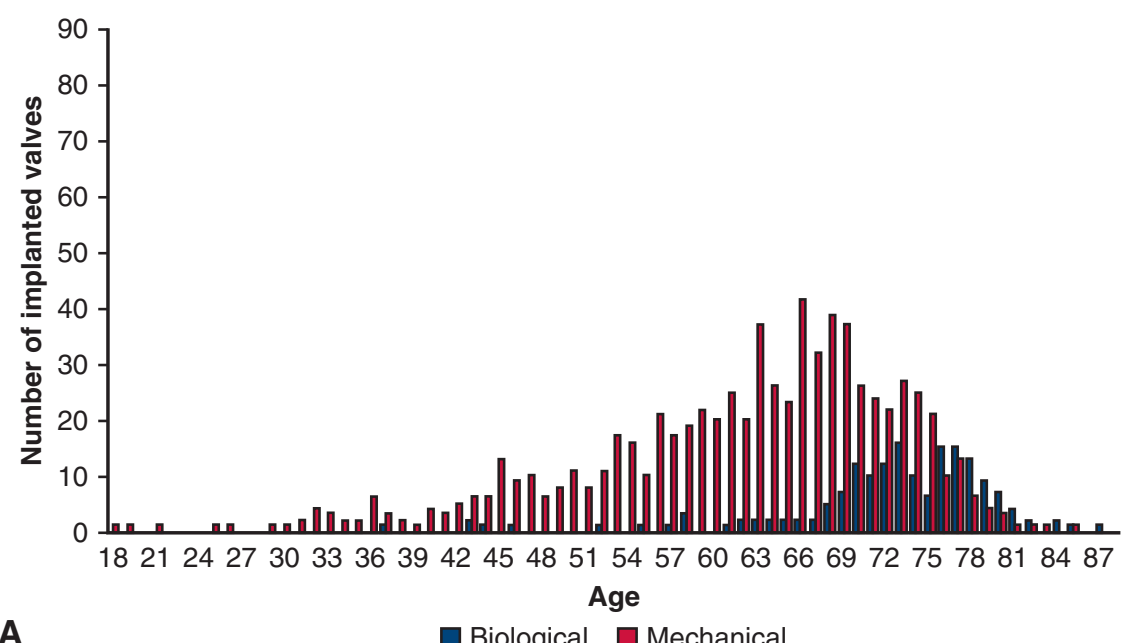

A

Biological $\square$ Mechanical

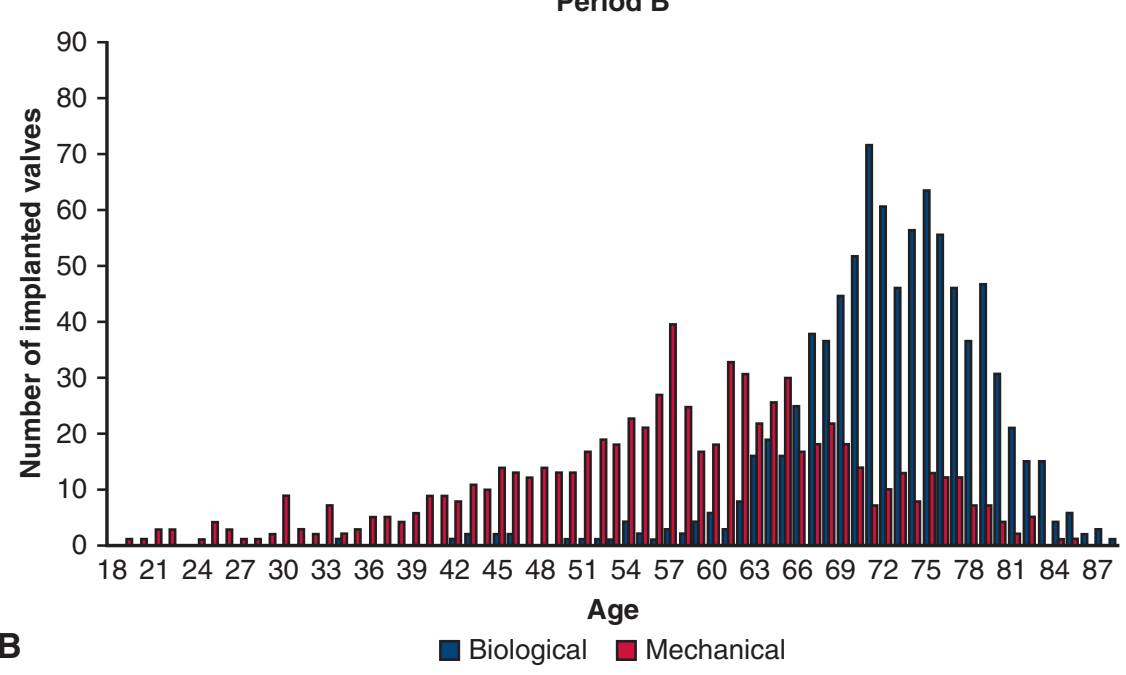

Period C

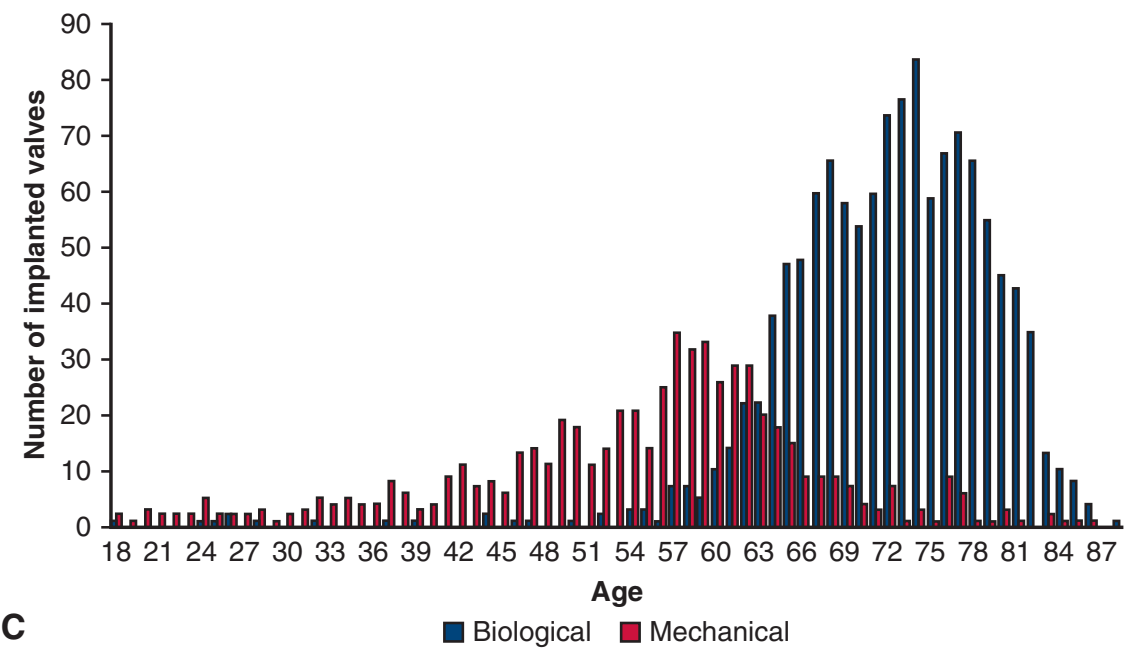

FIGURE 2. Mechanical and bioprosthetic valve use across 3 decades. Absolute number of bioprosthetic and mechanical valves implanted according to patient age and time of SAVR (period A: 1987-1996; B: 1997-2006; C: 2007-2016). Note the considerable increase in patients receiving bioprosthetic valves from period $\mathrm{A}$ to $\mathrm{C}$ and the decrease in mechanical valve use above the age of 65 years. The $X$-axis represents the age at SAVR. 
TABLE 3. Ten-year survival after primary surgical aortic valve replacement over three decades

\begin{tabular}{|c|c|c|c|c|c|}
\hline \multicolumn{6}{|c|}{ 10-y survival } \\
\hline & All patients & Period A 1987-1996 & Period B 1997-2006 & Period C 2007-2016 & $P$ value \\
\hline Overall cohort & 59.9 & 61.8 & 58.7 & 60.5 & .243 \\
\hline Isolated SAVR & 65.5 & 66.9 & 63.7 & 67.2 & .312 \\
\hline SAVR + CABG & 51.1 & 54.9 & 49.3 & 50.3 & .352 \\
\hline SAVR + MV procedure & 64.4 & 65.1 & 59.3 & 70.2 & .253 \\
\hline \multicolumn{6}{|l|}{ Isolated SAVR } \\
\hline$\geq 70 y$ & 48.8 & 49.7 & 47.5 & 50.2 & .772 \\
\hline $60-69$ y & 70.6 & 70.6 & 67.7 & 76.3 & .323 \\
\hline $50-59$ y & 81.3 & 76.4 & 80.9 & 85.6 & .294 \\
\hline Mechanical & 74.6 & 69.3 & 75.2 & 83.6 & .001 \\
\hline Biological & 55.7 & 56.6 & 53.6 & 58.7 & .450 \\
\hline Female & 66.7 & 66.7 & 65.7 & 66.8 & .676 \\
\hline Male & 64.6 & 67.0 & 62.0 & 67.8 & 287 \\
\hline High-risk patients (LES $\geq 20$ ) & 40.0 & N/A & 45.5 & 30.6 & .727 \\
\hline Intermediate-risk patients (LES 10-20) & 47.3 & N/A & 42.2 & 54.2 & 418 \\
\hline Low-risk patients $($ LES $<10)$ & 70.4 & N/A & 71.5 & 69.5 & .671 \\
\hline \multicolumn{6}{|l|}{ SAVR with CABG } \\
\hline$\geq 70 y$ & 41.0 & 40.2 & 39.2 & 44.5 & .447 \\
\hline $60-69 y$ & 61.3 & 63.7 & 59.9 & 59.8 & .909 \\
\hline $50-59$ y & 75.5 & 80.6 & 77.8 & 62.6 & .293 \\
\hline Mechanical & 57.9 & 55.4 & 62.3 & 54.4 & .381 \\
\hline Biological & 46.8 & 53.3 & 43.2 & 49.5 & .124 \\
\hline Female & 48.0 & 51.4 & 45.6 & 49.3 & .700 \\
\hline Male & 52.6 & 56.6 & 51.0 & 50.7 & .484 \\
\hline High-risk patients (LES $\geq 20$ ) & 23.6 & N/A & 20.0 & 24.6 & .814 \\
\hline Intermediate-risk patients (LES 10-20) & 46.1 & N/A & 37.6 & 52.4 & .322 \\
\hline Low-risk patients $(\mathrm{LES}<10$ ) & 55.2 & N/A & 58.2 & 52.2 & .412 \\
\hline
\end{tabular}

Values are presented as percentages. SAVR, Surgical aortic valve replacement; $C A B G$, coronary artery bypass grafting; $M V$, mitral valve; $L E S$, logistic European System for Cardiac Operative Risk Evaluation; N/A, not available.

patients aged 70 years or more. ${ }^{22,23}$ Patients with concomitant $\mathrm{CABG}$ reflect a population with more advanced heart disease and diminished life expectancy due to higher shortand long-term mortality compared with those undergoing isolated SAVR. ${ }^{24}$ Likewise, patients requiring complex or multivalvular surgery represent a group with higher risk. $^{24-26}$ These patients should be carefully selected and directed to high-volume centers. ${ }^{25}$

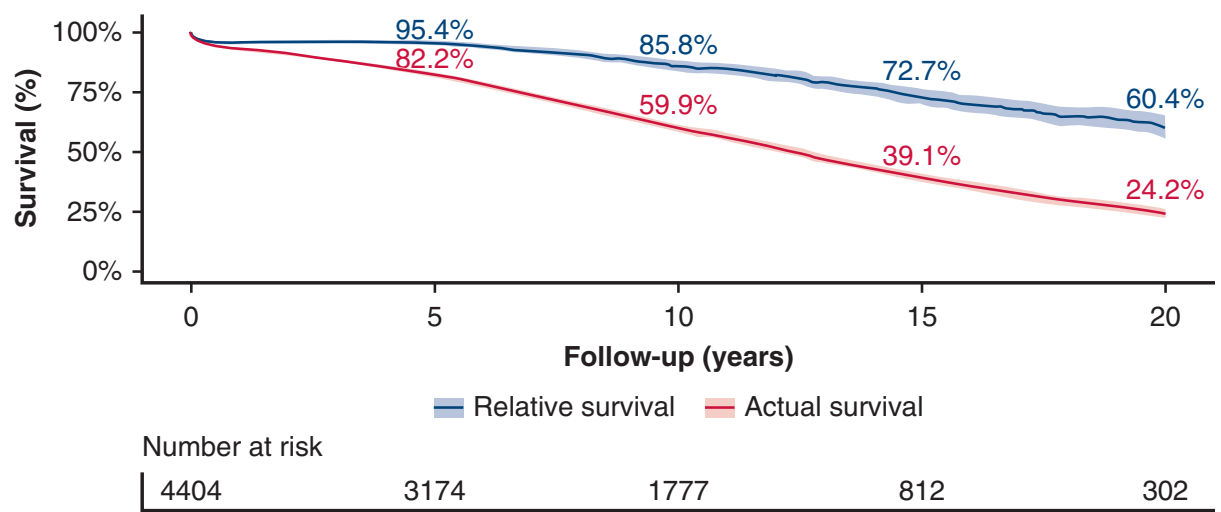

FIGURE 3. Long-term survival after SAVR. Actual survival of patients in the overall SAVR cohort (red line) and relative survival compared with the age-, gender-, and year-matched Dutch population (blue line). The relative survival after SAVR is approximately $85 \%$ at 10 and $60 \%$ at 20 years when compared with that of the matched general population. 


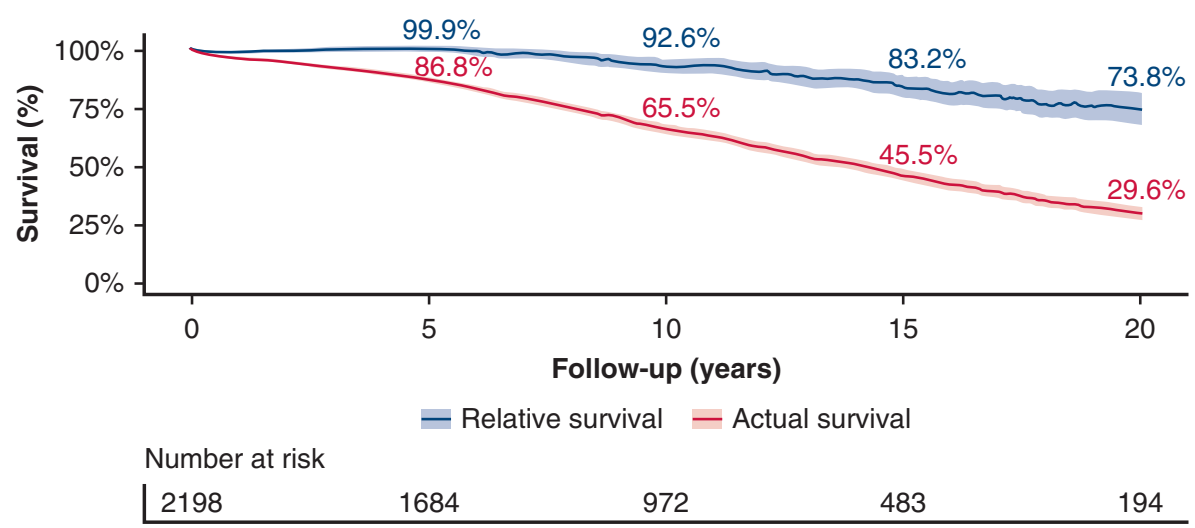

FIGURE 4. Long-term survival after primary isolated SAVR. Actual survival (red line) and relative survival compared with the age-, gender-, and yearmatched population (blue line). Note the relative survival of $73.8 \%$ after primary isolated SAVR at 20 years.

Prosthesis choice is an important element of treatment decisions in aortic valve disease. Both mechanical and bioprosthetic valves are associated with inherent risks. ${ }^{27} \mathrm{Me}-$ chanical valves require lifelong anticoagulation associated with bleeding events, and bioprosthetic valves are prone to degeneration, necessitating a second intervention in the long term. ${ }^{28}$ In our study, a 4-fold increase in bioprosthetic valve use was observed over the last 3 decades, mimicking a worldwide trend. ${ }^{28}$ The shift from mechanical to bioprosthetic valves was most prominent in patients aged 60 to 70 years. ${ }^{29}$ Additionally, the age profile of SAVR patients changed considerably, with an increasing number of elderly patients undergoing SAVR. These patients form the bulk of the contemporary SAVR population and received almost exclusively a bioprosthetic valve. Although the first randomized controlled trial comparing bioprosthetic and mechanical valves showed better survival in patients receiving mechanical valves, ${ }^{30}$ recent literature supports the benefit of bioprosthetic valves compared with mechanical valves in patients aged 60 years and older. ${ }^{28,31}$ Although younger patients might benefit from bioprosthetic valves, caution is warranted. ${ }^{32}$ Valve-in-valve TAVR in prospect might be an option when considering bioprosthetic valves in younger patients. ${ }^{33,34}$

Despite the increasing patient age and complexity, the 30-day mortality decreased or remained stable over the 30 -year observation period in the different cohorts. This may reflect advances in surgical technique and perioperative care over the last decades. ${ }^{35}$ Although long-term actual survival after SAVR is influenced by the competing risk of mortality due to other factors, relative survival provides a good estimate of the disease- and intervention-related risks, because it compares the survival of the investigated population with the survival of the matched general population. ${ }^{36}$ Glaser and colleagues ${ }^{37}$ reported a relative survival of $97 \%$ and $88 \%$ at 5 and 10 years after SAVR, respectively, and Kvidal and colleagues ${ }^{23}$ described a $74.9 \%$ relative survival at 15 years in a large SAVR cohort. In our study, the relative survival after isolated SAVR was similar to that of the age-, sex-, and year-matched Dutch population at 5 years, greater than $90 \%$ at 10 years, indicating an excellent long-term result. However, the decrease afterward in relative survival is not negligible and emphasizes the impact of disease- and intervention-related hazards in the extended long term. ${ }^{37}$

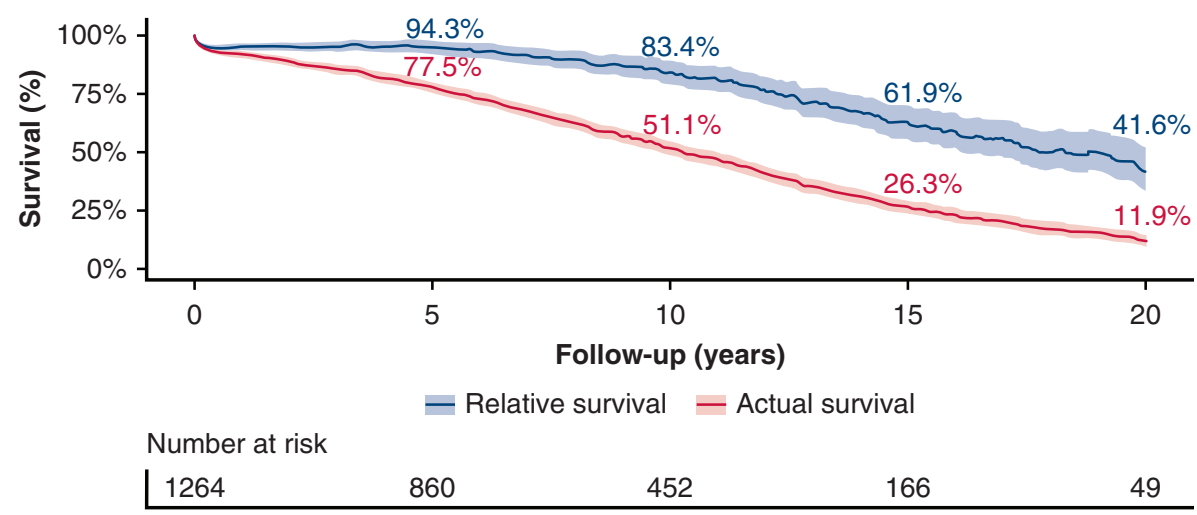

FIGURE 5. Long-term actual and relative survival after primary SAVR with concomitant CABG. Actual survival (red line) and relative survival compared with the age-, gender-, and year-matched population (blue line). Note the relative survival of $41.6 \%$ after SAVR with concomitant CABG at 20 years. 
Long-term survival in a large cohort undergoing surgical aortic valve replacement in our center during the last 30 years
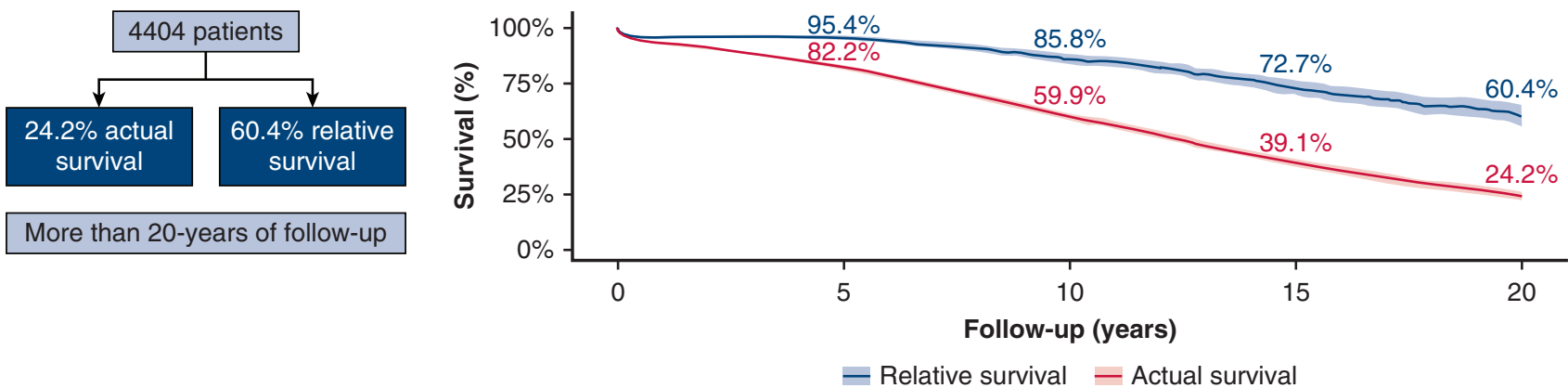

Number at risk

\begin{tabular}{|lllll}
4404 & 3174 & 1777 & 812 & 302 \\
\hline
\end{tabular}

We identify that the relative survival is $60 \%$ at 20 -years of follow-up. These excellent long-term results reinforce the role of surgical aortic valve replacement, especially in younger low-risk patients with long life expectancy.

FIGURE 6. Long-term actual and relative survivals in the overall cohort. Long-term survival after SAVR. Actual survival of patients in the overall SAVR cohort (red line) and relative survival compared with the age-, gender-, and year-matched Dutch population (blue line). Note the relative survival of $85.8 \%$ at 10 and $60.4 \%$ at 20 years, respectively.

The growing use of TAVR challenges the traditional role of SAVR in the treatment of aortic valve stenosis. In the light of recent trial results, the elderly SAVR population might have overlapping indications for both TAVR and SAVR in the future. ${ }^{7,8}$ In the current 5-year data regarding intermediate-risk patients with severe symptomatic aortic stenosis, there was no difference between the incidence of the composite end point of mortality and disabling stroke in patients receiving TAVR and SAVR, $47.9 \%$ and $43.4 \%$, respectively. ${ }^{38}$ The added value even translated to the lowrisk population. Patients classified as low risk had noninferior outcomes regarding the composite end point of mortality and disabling stroke at 2 years of follow-up, $5.3 \%$ and $6.7 \%$ in TAVR and SAVR, respectively. ${ }^{8}$ Further research regarding the long-term durability of TAVR and the use of TAVR in specific patient groups, such as patients with high anatomic risk, including bicuspid morphology, dilated aortic root, heavy annular calcification, and expected future coronary access, remain warranted. Regular formal heart team discussions are recommended by the clinical guidelines. ${ }^{5,6}$ These meetings allow for informed decisions in a multidisciplinary setting, where the preferred intervention can be discussed on the basis of the individual patient profile, local resources and expertise, and the evidence available on procedure-related risks and long-term results. ${ }^{39}$

\section{Study Limitations}

The results presented are based on data from a single center in The Netherlands. As with all retrospective studies, inherent shortcomings related to data capture are present. In addition, our study evaluated only survival as a longterm clinical outcome, because other important clinical outcomes (eg, quality of life, structural valve dysfunction or valve-related thromboembolic, and bleeding events) were not captured in our database. The amount of patients with newer-generation valves such as sutureless valves is low, which might yield different outcomes. Other potential limitations include selective outcome reporting.

\section{CONCLUSIONS}

The present study demonstrates the patient-related changes over time in patients receiving SAVR and the excellent SAVR-related outcomes over the last 3 decades. Isolated SAVR has proven itself with excellent long-term relative survival $(73.8 \%$ at 20 years in our study). The existing SAVR cohort overlaps with the expected future TAVR cohort; therefore, our findings may serve as a benchmark for future TAVR population studies.

\section{Conflict of Interest Statement}

The authors reported no conflicts of interest.

The Journal policy requires editors and reviewers to disclose conflicts of interest and to decline handling or reviewing manuscripts for which they may have a conflict of interest. The editors and reviewers of this article have no conflicts of interest.

\section{References}

1. Effler DB, Favaloro R, Groves LK. Heart valve replacement. Clinical experience. Ann Thorac Surg. 1965;1:4-24.

2. Lee R, Li S, Rankin JS, O'Brien SM, Gammie JS, Peterson ED, et al. Fifteen-year outcome trends for valve surgery in North America. Ann Thorac Surg. 2011;91: 677-84.

3. Thourani VH, Suri RM, Gunter RL, Sheng S, O'Brien SM, Ailawadi G, et al. Contemporary real-world outcomes of surgical aortic valve replacement in 141,905 low-risk, intermediate-risk, and high-risk patients. Ann Thorac Surg. 2015;99:55-61. 
4. Cribier A, Eltchaninoff H, Bash A, Borenstein N, Tron C, Bauer F, et al. Percutaneous transcatheter implantation of an aortic valve prosthesis for calcific aortic stenosis. Circulation. 2002;106:3006.

5. Baumgartner H, Falk V, Bax JJ, De Bonis M, Hamm C, Holm PJ, et al. 2017 ESC/ EACTS guidelines for the management of valvular heart disease. Eur Heart J. 2017:38:2739-91.

6. Nishimura RA, Otto CM, Bonow RO, Carabello BA, Erwin JP III, Fleisher LA, et al. 2017 AHA/ACC focused update of the 2014 AHA/ ACC guideline for the management of patients with valvular heart disease: a report of the American College of Cardiology/American Heart Association task force on clinical practice guidelines. Circulation. 2017;135: e1159-95.

7. Mack MJ, Leon MB, Thourani VH, Makkar R, Kodali SK, Russo M, et al. Transcatheter aortic-valve replacement with a balloon-expandable valve in low-risk patients. N Engl J Med. 2019;380:1695-705.

8. Popma JJ, Deeb GM, Yakubov SJ, Mumtaz M, Gada H, O'Hair D, et al. Transcatheter aortic-valve replacement with a self-expanding valve in low-risk patients. N Engl J Med. 2019;380:1706-15.

9. Perme M, Pavlic K. Nonparametric relative survival analysis with the R Package relsurv. J Stat Softw. 2018;87:27.

10. The Human Mortality Database; 2019. Available at: https://www.mortality.org/. Accessed May 21, 2021.

11. Pohar M, Stare J. Relative survival analysis in R. Comput Methods Programs Biomed. 2006;81:272-8.

12. Pohar M, Stare J. Making relative survival analysis relatively easy. Comput Biol Med. 2007:37:1741-9.

13. Bonow RO, Greenland P. Population-wide trends in aortic stenosis incidence and outcomes. Circulation. 2015;131:969-71.

14. Maganti K, Rigolin VH, Sarano ME, Bonow RO. Valvular heart disease: diagnosis and management. Mayo Clin Proc. 2010;85:483-500.

15. Barreto-Filho JA, Wang Y, Dodson JA, Desai MM, Sugeng L, Geirsson A, et al. Trends in aortic valve replacement for elderly patients in the United States, 19992011. JAMA. 2013;310:2078-85.

16. Zoghbi WA. Cardiovascular imaging: a glimpse into the future. Methodist Debakey Cardiovasc J. 2014;10:139-45.

17. Iung B, Baron G, Butchart EG, Delahaye F, Gohlke-Barwolf C, Levang OW, et al. A prospective survey of patients with valvular heart disease in Europe: the Euro heart survey on valvular heart disease. Eur Heart J. 2003;24:1231-43.

18. Gaede L, Blumenstein J, Kim WK, Liebetrau C, Dorr O, Nef H, et al. Trends in aortic valve replacement in Germany in 2015: transcatheter versus isolated surgical aortic valve repair. Clin Res Cardiol. 2017;106:411-9.

19. Kundi H, Strom JB, Valsdottir LR, Elmariah S, Popma JJ, Shen C, et al. Trends in isolated surgical aortic valve replacement according to hospital-based transcatheter aortic valve replacement volumes. JACC Cardiovasc Interv. 2018;11: 2148-56.

20. Davierwala PM, Maganti M, Yau TM. Decreasing significance of left ventricular dysfunction and reoperative surgery in predicting coronary artery bypass grafting-associated mortality: a twelve-year study. J Thorac Cardiovasc Surg. 2003; 126:1335-44.

21. Clough RA, Leavitt BJ, Morton JR, Plume SK, Hernandez F, Nugent W, et al. The effect of comorbid illness on mortality outcomes in cardiac surgery. Arch Surg. 2002;137:428-33.

22. Rapp AH, Hillis LD, Lange RA, Cigarroa JE. Prevalence of coronary artery disease in patients with aortic stenosis with and without angina pectoris. Am J Cardiol. 2001;87:1216-7. A7.
23. Kvidal P, Bergstrom R, Horte LG, Stahle E. Observed and relative survival after aortic valve replacement. J Am Coll Cardiol. 2000;35:747-56.

24. Beckmann A, Meyer R, Lewandowski J, Frie M, Markewitz A, Harringer W German heart Surgery report 2017: the annual updated registry of the German Society for Thoracic and Cardiovascular Surgery. J Thorac Cardiovasc Surg. 2018; 66:608-21.

25. Kilic A, Shah AS, Conte JV, Baumgartner WA, Yuh DD. Operative outcomes in mitral valve surgery: combined effect of surgeon and hospital volume in a population-based analysis. J Thorac Cardiovasc Surg. 2013;146:638-46.

26. Vassileva CM, Li S, Thourani VH, Suri RM, Williams ML, Lee R, et al. Outcome characteristics of multiple-valve surgery: comparison with single-valve procedures. Innovations (Phila). 2014;9:27-32.

27. Head SJ, Celik M, Kappetein AP. Mechanical versus bioprosthetic aortic valve replacement. Eur Heart J. 2017;38:2183-91.

28. Goldstone AB, Chiu P, Baiocchi M, Lingala B, Patrick WL, Fischbein MP, et al Mechanical or biologic prostheses for aortic-valve and mitral-valve replacement. N Engl J Med. 2017;377:1847-57.

29. Huygens SA, Etnel JRG, Hanif M, Bekkers JA, Bogers A, Rutten-van Molken M, et al. Bioprosthetic aortic valve replacement in elderly patients: meta-analysis and microsimulation. J Thorac Cardiovasc Surg. 2019;157:2189-97.e14.

30. Hammermeister K, Sethi GK, Henderson WG, Grover FL, Oprian C, Rahimtoola SH. Outcomes 15 years after valve replacement with a mechanical versus a bioprosthetic valve: final report of the Veterans Affairs randomized trial. J Am Coll Cardiol. 2000;36:1152-8.

31. Glaser N, Jackson V, Holzmann MJ, Franco-Cereceda A, Sartipy U. Aortic valve replacement with mechanical vs. biological prostheses in patients aged 50-69 years. Eur Heart J. 2016;37:2658-67.

32. Hirji SA, Kolkailah AA, Ramirez-Del Val F, Lee J, McGurk S, Pelletier M, et al Mechanical versus bioprosthetic aortic valve replacement in patients aged 50 years and younger. Ann Thorac Surg. 2018;106:1113-20.

33. Reul RM, Ramchandani MK, Reardon MJ. Transcatheter aortic valve-in-valve procedure in patients with bioprosthetic structural valve deterioration. Methodist Debakey Cardiovasc J. 2017;13:132-41.

34. Dvir D, Webb J, Brecker S, Bleiziffer S, Hildick-Smith D, Colombo A, et al Transcatheter aortic valve replacement for degenerative bioprosthetic surgical valves: results from the global valve-in-valve registry. Circulation. 2012;126: 2335-44.

35. Pennington DG. The impact of new technology on cardiothoracic surgical practice. Ann Thorac Surg. 2006;81:10-8.

36. Sarfati D, Blakely T, Pearce N. Measuring cancer survival in populations: relative survival vs cancer-specific survival. Int J Epidemiol. 2010;39:598-610.

37. Glaser N, Persson M, Jackson V, Holzmann MJ, Franco-Cereceda A, Sartipy U Loss in life expectancy after surgical aortic valve replacement: SWEDEHEART study. J Am Coll Cardiol. 2019;74:26-33.

38. Makkar RR, Thourani VH, Mack MJ, Kodali SK, Kapadia S, Webb JG, et al Five-year outcomes of transcatheter or surgical aortic-valve replacement. $N$ Engl J Med. 2020;382:799-809.

39. de Jaegere PPT, de Weger A, den Heijer P, Verkroost M, Baan J, de Kroon T, et al. Treatment decision for transcatheter aortic valve implantation: the role of the heart team : Position statement paper of the Dutch Working Group of Transcatheter Heart Interventions. Neth Heart J. 2020;28:229-39.

Key Words: aortic valve disease, aortic valve replacement, aortic valve stenosis, intervention 


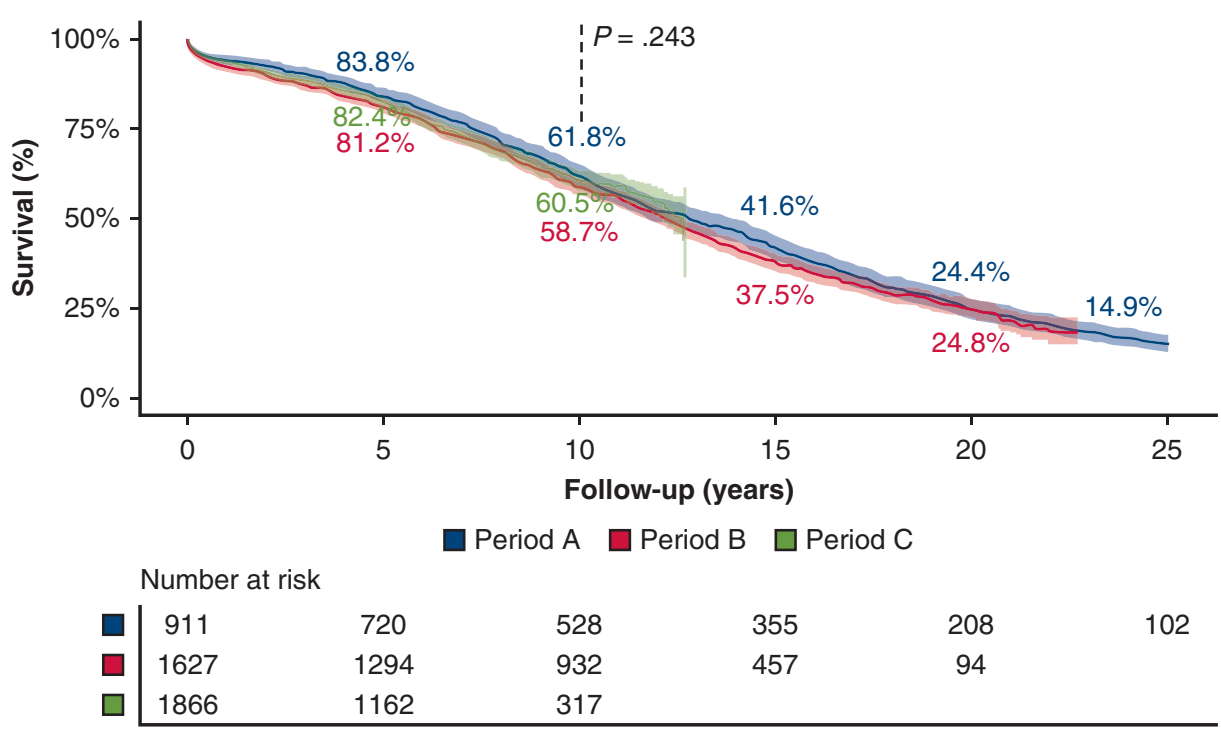

FIGURE E1. Long-term survival after SAVR in the overall cohort according to period operated. Actual survival of patients in the overall SAVR cohort. Patients operated between 1987 and 1996 (period A) are shown with the red line; patients operated between 1997 and 2006 (period B) are shown with the blue line; and patients operated between 2007 and 2017 (period C) are shown with the orange line. Comparison within periods is done for 10 years of followup and shown as $P$ value.

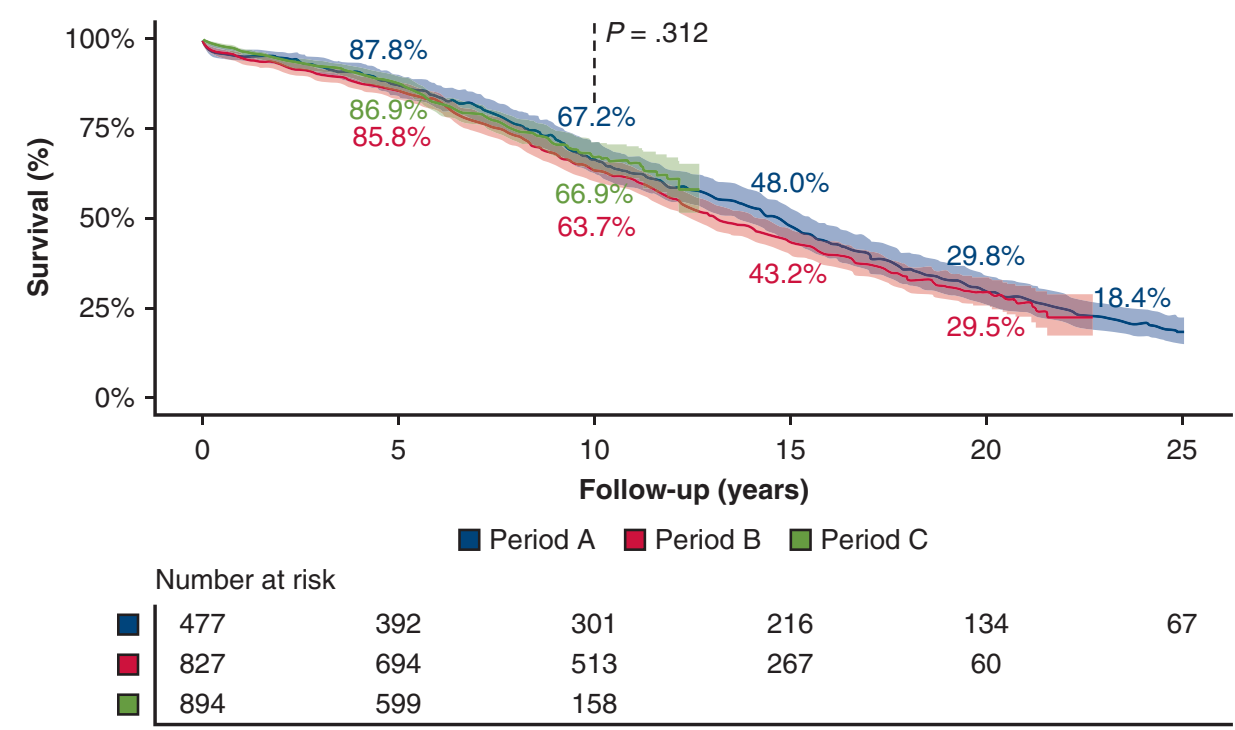

FIGURE E2. Long-term survival after primary isolated SAVR according to period operated. Actual survival of patients with primary isolated SAVR. Patients operated between 1987 and 1996 (period A) are shown with the red line; patients operated between 1997 and 2006 (period B) are shown with the blue line; and patients operated between 2007 and 2017 (period C) are shown with the orange line. Comparison within periods is done for 10 years of follow-up and shown as $P$ value. 


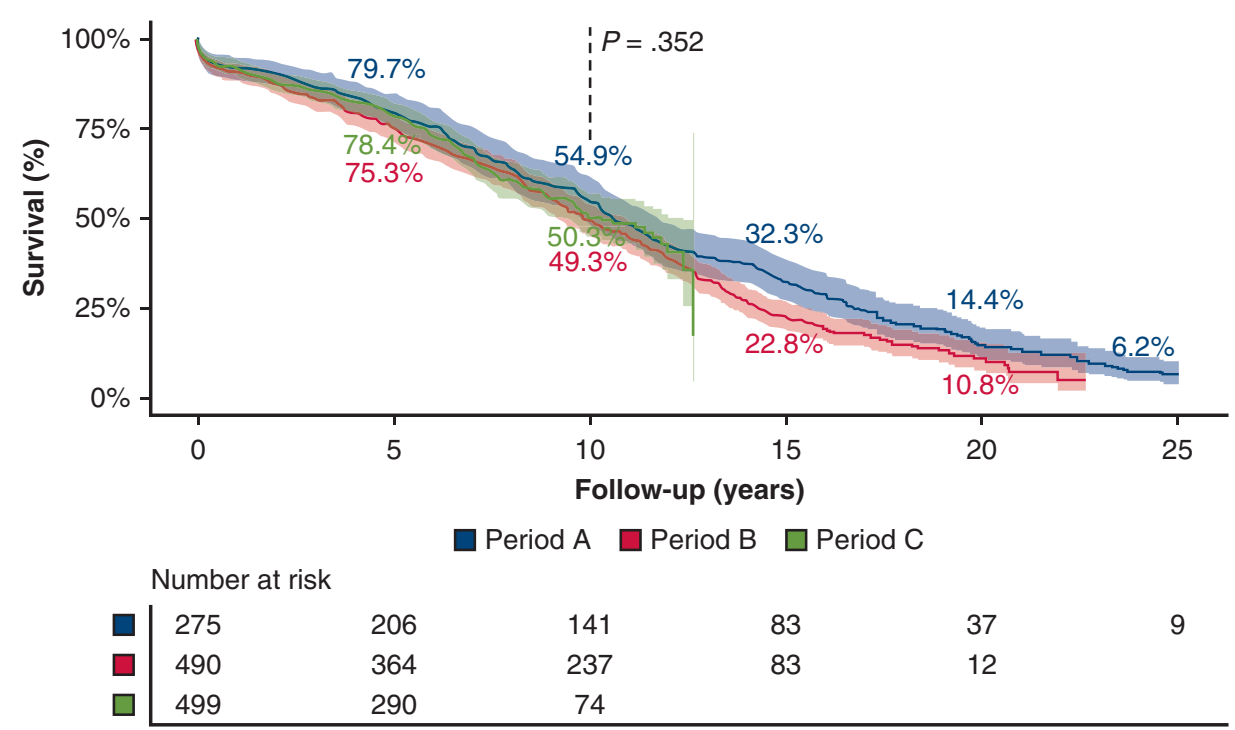

FIGURE E3. Long-term actual after primary SAVR with concomitant CABG according to period operated. Actual survival of patients with primary SAVR and concomitant CABG. Patients operated between 1987 and 1996 (period A) are shown with the red line; patients operated between 1997 and 2006 (period B) are shown with the blue line; and patients operated between 2007 and 2017 (period C) are shown with the orange line. Comparison within periods is done for 10 years of follow-up and shown as $P$ value. 
TABLE E1. Baseline and procedural characteristics over 3 decades in patients undergoing primary isolated surgical aortic valve replacement

\begin{tabular}{|c|c|c|c|c|c|}
\hline & $\begin{array}{l}\text { All patients } \\
(n=2198)\end{array}$ & $\begin{array}{l}\text { Period A 1987-1996 } \\
\quad(n=477)\end{array}$ & $\begin{array}{l}\text { Period B 1997-2006 } \\
\quad(\mathrm{n}=827)\end{array}$ & $\begin{array}{l}\text { Period C 2007-2016 } \\
\quad(n=894)\end{array}$ & $\begin{array}{c}\text { Chi-square } \\
P \text { value }\end{array}$ \\
\hline Age at operation, y (mean $\pm \mathrm{SD})$ & $65.0 \pm 12.0$ & $63.7 \pm 10.7$ & $65.1 \pm 12.4$ & $65.5 \pm 12.3$ & .029 \\
\hline$<40$ & 3.6 & 2.9 & 3.9 & 3.8 & .474 \\
\hline $40-49$ & 7.6 & 8.4 & 8.1 & 6.6 & .188 \\
\hline $50-59$ & 15.8 & 16.8 & 15.5 & 15.7 & .646 \\
\hline $60-69$ & 31.4 & 39.0 & 28.4 & 30.1 & .004 \\
\hline $70-79$ & 35.0 & 31.0 & 36.9 & 35.3 & .197 \\
\hline$\geq 80$ & 6.6 & 1.9 & 7.3 & 8.5 & $<.001$ \\
\hline Female & 41.1 & 38.8 & 45.6 & 38.1 & .387 \\
\hline \multicolumn{6}{|l|}{ Indication $(\mathrm{n}=2198)$} \\
\hline AS & 68.2 & 56.8 & 67.2 & 75.3 & $<.001$ \\
\hline $\mathrm{AR}$ & 13.5 & 13.2 & 14.6 & 12.6 & .606 \\
\hline Combined & 18.1 & 29.8 & 18.1 & 11.7 & $<.001$ \\
\hline Bicuspid aortic valve & 20.9 & 35.2 & 20.4 & 13.8 & $<.001$ \\
\hline Endocarditis & 5.4 & 4.8 & 4.5 & 6.5 & .120 \\
\hline $\begin{array}{l}\text { Logistic euroSCORE }(\mathrm{n}=1239) \\
\quad(\text { median, IQR })\end{array}$ & $4.2(2.4-7.0)$ & N/A & $4.2(2.2-7.2)$ & $4.2(2.4-6.9)$ & .965 \\
\hline Logistic euroSCORE $\geq 10 \mathrm{n}(\%)$ & 12.7 & & 16.2 & 11.3 & .019 \\
\hline Logistic euroSCORE $\geq 20 \mathrm{n}(\%)$ & 3.0 & & 3.2 & 2.9 & .795 \\
\hline Previous cardiac operation & 6.3 & 6.5 & 7.0 & 5.6 & .400 \\
\hline Creatinine $\geq 2 \mathrm{mg} / \mathrm{dL}$ & 2.3 & 2.1 & 1.9 & 2.7 & .400 \\
\hline Previous hemodialysis & 0.7 & 0.4 & 0.6 & 0.9 & .287 \\
\hline Atrial fibrillation & 12.9 & 13.8 & 13.3 & 12.1 & .325 \\
\hline Diabetes mellitus & 12.3 & 7.8 & 8.9 & 17.9 & $<.001$ \\
\hline Cardiac decompensation & 14.2 & 23.1 & 12.7 & 10.9 & $<.001$ \\
\hline Hypertension & 34.4 & 22.4 & 28.4 & 46.4 & $<.001$ \\
\hline Hypercholesterolemia & 15.2 & 5.0 & 12.3 & 23.3 & $<.001$ \\
\hline Previous myocardial infarction & 5.6 & 5.5 & 4.4 & 6.7 & .187 \\
\hline Previous PCI & 5.7 & 1.9 & 4.2 & 9.2 & $<.001$ \\
\hline COPD & 11.2 & 9.0 & 11.1 & 12.5 & .051 \\
\hline History of cancer & 6.7 & 2.1 & 7.3 & 8.7 & $<.001$ \\
\hline Stroke & 8.4 & 4.0 & 8.0 & 11.1 & $<.001$ \\
\hline Arterial disease & 3.0 & 1.0 & 2.5 & 4.5 & $<.001$ \\
\hline Peripheral & 2.6 & 1.0 & 2.3 & 3.8 & .002 \\
\hline Carotid & 0.5 & 0 & 0.4 & 0.8 & .035 \\
\hline \multicolumn{6}{|l|}{$\operatorname{LVEF}(\mathrm{n}=2006)$} \\
\hline Good & 81.8 & 78.4 & 82.8 & 82.4 & .161 \\
\hline Reduced & 14.9 & 15.1 & 14.7 & 14.8 & .933 \\
\hline Severely reduced & 3.3 & 6.5 & 2.5 & 2.8 & .005 \\
\hline $\begin{array}{l}\text { Urgency }(\mathrm{n}=1942) \\
\quad(\text { Semi-) Elective }(>24 \mathrm{~h}) \\
\text { Urgent }(<24 \mathrm{~h})\end{array}$ & $\begin{array}{c}98.7 \\
1.3\end{array}$ & $\begin{array}{c}98.6 \\
1.4\end{array}$ & $\begin{array}{c}1.3 \\
98.7\end{array}$ & $\begin{array}{c}1.3 \\
98.7\end{array}$ & .910 \\
\hline $\begin{array}{l}\text { Prosthesis type } \\
\text { Mechanical } \\
\text { Bioprosthetic }\end{array}$ & $\begin{array}{l}48.8 \\
51.2\end{array}$ & $\begin{array}{l}82.0 \\
18.0\end{array}$ & $\begin{array}{l}46.9 \\
53.1\end{array}$ & $\begin{array}{l}32.9 \\
67.1\end{array}$ & $<.001$ \\
\hline Prosthesis size & $23.6 \pm 2.4$ & $24.0 \pm 2.3$ & $24.0 \pm 2.5$ & $23.1 \pm 2.3$ & $<.001$ \\
\hline 19 & 3.9 & 1.5 & 2.3 & 6.7 & $<.001$ \\
\hline 21 & 22.5 & 17.9 & 20.7 & 26.7 & $<.001$ \\
\hline
\end{tabular}


TABLE E1. Continued

\begin{tabular}{cccccc}
\hline & $\begin{array}{c}\text { All patients } \\
(\mathbf{n}=\mathbf{2 1 9 8})\end{array}$ & $\begin{array}{c}\text { Period A 1987-1996 } \\
(\mathbf{n}=\mathbf{4 7 7})\end{array}$ & $\begin{array}{c}\text { Period B 1997-2006 } \\
(\mathbf{n}=\mathbf{8 2 7})\end{array}$ & $\begin{array}{c}\text { Period C 2007-2016 } \\
(\mathbf{n}=\mathbf{8 9 4})\end{array}$ & $\begin{array}{c}\text { Chi-square } \\
\boldsymbol{P} \text { value }\end{array}$ \\
\hline 23 & 32.0 & 32.8 & 30.7 & 32.7 & .884 \\
25 & 24.9 & 30.5 & 24.8 & 22.1 & .001 \\
27 & 11.9 & 12.2 & 13.9 & 10.0 \\
29 & 4.4 & 5.0 & 7.0 & .106 \\
\hline
\end{tabular}

Values are presented as $\mathrm{n}(\%)$ or as mean $\pm \mathrm{SD}$ or median (interquartile range) if otherwise stated. $S D$, Standard deviation; $A S$, aortic stenosis; $A R$, aortic regurgitation; euro$S C O R E$, European System for Cardiac Operative Risk Evaluation; $I Q R$, interquartile range; $N / A$, not available; $P C I$, percutaneous coronary intervention; $C O P D$, chronic obstructive pulmonary disease; $L V E F$, left ventricular ejection function. 
TABLE E2. Baseline and procedural characteristics over three decades in patients undergoing isolated surgical aortic valve replacement + coronary artery bypass grafting

\begin{tabular}{|c|c|c|c|c|c|}
\hline & $\begin{array}{c}\text { All patients } \\
(\mathrm{n}=1264)\end{array}$ & $\begin{array}{l}\text { Period A 1987-1996 } \\
\quad(n=275)\end{array}$ & $\begin{array}{l}\text { Period B 1997-2006 } \\
\quad(n=490)\end{array}$ & $\begin{array}{c}\text { Period C 2007-2016 } \\
\quad(n=499)\end{array}$ & $\begin{array}{c}\text { Chi-square } \\
P \text { value }\end{array}$ \\
\hline Age at operation, y (mean $\pm \mathrm{SD})$ & $70.1 \pm 8.3$ & $68.5 \pm 8.0$ & $70.0 \pm 8.5$ & $71.0 \pm 8.2$ & $<.001$ \\
\hline $40-49$ & 2.5 & 1.8 & 3.3 & 2.2 & .938 \\
\hline $50-59$ & 9.2 & 13.1 & 9.4 & 6.8 & .004 \\
\hline $60-69$ & 29.9 & 35.3 & 26.1 & 30.7 & .376 \\
\hline $70-79$ & 48.1 & 44.4 & 52.7 & 45.7 & .897 \\
\hline$\geq 80$ & 10.3 & 5.5 & 8.6 & 14.6 & $<.001$ \\
\hline Female & 30.1 & 33.5 & 32.0 & 26.3 & .023 \\
\hline \multicolumn{6}{|l|}{ Indication $(\mathrm{n}=1264)$} \\
\hline AS & 80.2 & 70.2 & 80.8 & 85.2 & $<.001$ \\
\hline AR & 8.8 & 9.1 & 9.2 & 8.2 & .632 \\
\hline Combined & 10.9 & 20.4 & 10.0 & 6.6 & $<.001$ \\
\hline Bicuspid aortic valve & 10.5 & 19.3 & 9.0 & 7.2 & $<.001$ \\
\hline Endocarditis & 1.5 & 2.2 & 1.6 & 1.0 & .186 \\
\hline $\begin{array}{l}\text { Logistic euroSCORE }(\mathrm{n}=697) \\
\quad(\text { median, IQR })\end{array}$ & $5.3(3.3-8.7)$ & N/A & $5.5(3.7-8.4)$ & $5.3(3.2-8.9)$ & .977 \\
\hline Logistic euroSCORE $\geq 10 \mathrm{n}(\%)$ & 19.1 & & 17.7 & 19.6 & .552 \\
\hline Logistic euroSCORE $\geq 20 \mathrm{n}(\%)$ & 5.6 & & 5.1 & 5.8 & .694 \\
\hline Previous cardiac operation & 5.5 & 8.7 & 6.3 & 2.8 & $<.001$ \\
\hline Creatinine $\geq 2 \mathrm{mg} / \mathrm{dL}$ & 2.8 & 2.5 & 2.7 & 3.0 & .686 \\
\hline Previous hemodialysis & 0.9 & 1.1 & 0.6 & 1.0 & .984 \\
\hline Atrial fibrillation & 12.5 & 13.1 & 12.0 & 12.6 & .911 \\
\hline Diabetes mellitus & 21.2 & 8.0 & 20.0 & 29.7 & $<0.001$ \\
\hline Cardiac decompensation & 15.6 & 18.5 & 16.3 & 13.2 & .043 \\
\hline Hypertension & 41.2 & 22.5 & 31.4 & 61.1 & $<.001$ \\
\hline Hypercholesterolemia & 21.8 & 6.9 & 17.8 & 34.1 & $<.001$ \\
\hline Previous myocardial infarction & 24.4 & 20.0 & 24.7 & 26.7 & .046 \\
\hline Previous PCI & 10.2 & 5.8 & 7.3 & 15.4 & $<.001$ \\
\hline COPD & 9.9 & 7.3 & 8.6 & 12.6 & .010 \\
\hline History of cancer & 7.5 & 3.3 & 6.1 & 11.2 & $<.001$ \\
\hline Stroke & 9.3 & 4.7 & 8.2 & 12.8 & $<.001$ \\
\hline Arterial disease & 8.4 & 5.8 & 6.5 & 11.6 & .002 \\
\hline Peripheral & 7.2 & 5.5 & 5.7 & 9.6 & .016 \\
\hline Carotid & 1.5 & 0.4 & 1.4 & 2.2 & .044 \\
\hline \multicolumn{6}{|l|}{$\operatorname{LVEF}(n=1185)$} \\
\hline Good & 75.7 & 75.8 & 76.8 & 74.5 & .589 \\
\hline Reduced & 20.5 & 17.8 & 19.7 & 22.6 & .114 \\
\hline Severely reduced & 3.8 & 6.4 & 3.5 & 2.9 & .033 \\
\hline $\begin{array}{l}\text { Urgency }(\mathrm{n}=1104) \\
\qquad \text { Semi-) Elective }(>24 \mathrm{~h}) \\
\text { Urgent }(<24 \mathrm{~h})\end{array}$ & $\begin{array}{c}98.6 \\
1.4\end{array}$ & $\begin{array}{c}99.4 \\
0.6\end{array}$ & $\begin{array}{c}98.5 \\
1.5\end{array}$ & $\begin{array}{c}98.5 \\
1.5\end{array}$ & .536 \\
\hline Prosthesis type & & & & & $<.001$ \\
\hline Mechanical & 36.1 & 74.9 & 32.2 & 18.4 & \\
\hline Biological & 63.9 & 25.1 & 67.8 & 81.6 & \\
\hline Prosthesis size & $23.5 \pm 2.2$ & $23.6 \pm 2.1$ & $23.7 \pm 2.3$ & $23.2 \pm 2.1$ & .003 \\
\hline 19 & 3.8 & 2.2 & 2.4 & 6.0 & .003 \\
\hline 21 & 21.6 & 20.0 & 21.8 & 22.2 & .495 \\
\hline
\end{tabular}


TABLE E2. Continued

\begin{tabular}{cccccc}
\hline & $\begin{array}{c}\text { All patients } \\
(\mathbf{n}=\mathbf{1 2 6 4})\end{array}$ & $\begin{array}{c}\text { Period A 1987-1996 } \\
(\mathbf{n}=\mathbf{2 7 5})\end{array}$ & $\begin{array}{c}\text { Period B 1997-2006 } \\
(\mathbf{n}=\mathbf{4 9 0})\end{array}$ & $\begin{array}{c}\text { Period C 2007-2016 } \\
(\mathbf{n}=\mathbf{4 9 9})\end{array}$ & $\begin{array}{c}\text { Chi-square } \\
\boldsymbol{P} \text { value }\end{array}$ \\
\hline 23 & 35.5 & 38.9 & 34.5 & 34.7 & .296 \\
25 & 26.3 & 24.7 & 24.9 & 28.7 & .181 \\
27 & 10.9 & 12.7 & 13.5 & 7.4 & .008 \\
29 & 1.5 & 1.5 & 2.2 & 0.8 \\
\hline
\end{tabular}

$S D$, Standard deviation; $A S$, aortic stenosis; $A R$, aortic regurgitation; euroSCORE, European System for Cardiac Operative Risk Evaluation; $I Q R$, interquartile range; $N / A$, not available; $P C I$, percutaneous coronary intervention; $C O P D$, chronic obstructive pulmonary disease; $L V E F$, left ventricular ejection function.

TABLE E3. Thirty-day mortality after primary surgical aortic valve replacement over 3 decades

\begin{tabular}{|c|c|c|c|c|c|}
\hline \multicolumn{6}{|c|}{ 30-d mortality } \\
\hline & All patients & Period A 1987-1996 & Period B 1997-2006 & Period C 2007-2016 & $P$ value \\
\hline Overall cohort & $2.7(4157)$ & $2.7(837)$ & $3.7(1555)$ & $1.8(1765)$ & .003 \\
\hline Isolated SAVR & $1.5(2198)$ & $1.9(477)$ & $1.8(827)$ & $0.9(894)$ & .190 \\
\hline $\mathrm{SAVR}+\mathrm{CABG}$ & $3.9(1264)$ & $4.1(275)$ & $4.7(490)$ & $3.0(499)$ & .384 \\
\hline SAVR + MV procedure & $4.8(235)$ & $3.8(57)$ & $7.7(92)$ & $2.3(86)$ & .220 \\
\hline \multicolumn{6}{|l|}{ Isolated SAVR } \\
\hline$\geq 70 y$ & $2.5(914)$ & $3.8(157)$ & $3.0(365)$ & $1.5(392)$ & .224 \\
\hline $60-69$ y & $0.1(690)$ & $0.5(186)$ & $0(235)$ & $0(269)$ & .258 \\
\hline $50-59$ y & $1.7(348)$ & $2.5(80)$ & $1.6(128)$ & $1.4(140)$ & .811 \\
\hline Mechanical & $1.7(1073)$ & $2.1(391)$ & $2.1(388)$ & 0.7 (294) & .293 \\
\hline Biological & $1.3(1125)$ & $1.2(86)$ & $1.6(439)$ & $1.0(600)$ & .700 \\
\hline Female & $1.3(903)$ & $2.2(185)$ & $1.9(377)$ & $0.3(341)$ & .104 \\
\hline Male & $1.5(1295)$ & $1.7(292)$ & $1.8(450)$ & $1.3(553)$ & .776 \\
\hline High-risk patients (LES $\geq 20$ ) & $8.3(37)$ & N/A & $9.1(11)$ & $7.9(26)$ & .936 \\
\hline Intermediate-risk patients (LES 10-20) & $2.5(120)$ & N/A & $2.2(45)$ & $2.7(75)$ & .873 \\
\hline Low-risk patients (LES <10) & $0.7(1082)$ & N/A & $1.1(289)$ & $0.5(793)$ & .302 \\
\hline \multicolumn{6}{|l|}{ SAVR with CABG } \\
\hline$\geq 70 y$ & $4.8(738)$ & $5.2(137)$ & $5.3(300)$ & $4.0(301)$ & .719 \\
\hline $60-69$ y & $2.7(378)$ & $3.2(97)$ & $3.9(128)$ & $1.3(153)$ & .380 \\
\hline $50-59$ y & $0.9(116)$ & $0(36)$ & $2.2(46)$ & $0(34)$ & .467 \\
\hline Mechanical & $4.6(456)$ & $4.9(206)$ & $4.5(158)$ & $4.3(92)$ & .975 \\
\hline Biological & $3.5(808)$ & $1.4(69)$ & $4.8(332)$ & $2.7(407)$ & .184 \\
\hline Female & $4.8(380)$ & $4.4(92)$ & $5.1(157)$ & $4.6(131)$ & .957 \\
\hline Male & $3.5(884)$ & $3.9(183)$ & $4.5(333)$ & $2.5(368)$ & .325 \\
\hline High-risk patients (LES $\geq 20$ ) & $12.8(39)$ & N/A & $10.0(10)$ & $13.8(29)$ & .742 \\
\hline Intermediate-risk patients (LES 10-20) & $5.4(94)$ & N/A & $4.0(25)$ & $5.9(69)$ & .725 \\
\hline Low-risk patients (LES <10) & $2.1(564)$ & N/A & $3.1(163)$ & $1.8(401)$ & .323 \\
\hline
\end{tabular}

Values are given in percentages with (number of patients). SAVR, Surgical aortic valve replacement; $C A B G$, coronary artery bypass grafting; $M V$, mitral valve; $L E S$, logistic European System for Cardiac Operative Risk Evaluation; N/A, not available. 
TABLE E4. 1-y survival after primary surgical aortic valve replacement over 3 decades

\begin{tabular}{|c|c|c|c|c|c|}
\hline \multicolumn{6}{|c|}{ 1-y survival } \\
\hline & All patients & Period A 1987-1996 & Period B 1997-2006 & Period C 2007-2016 & $P$ value \\
\hline Overall cohort & 93.5 & 94.4 & 92.0 & 94.4 & .012 \\
\hline Isolated SAVR & 95.7 & 95.7 & 94.7 & 96.6 & .154 \\
\hline $\mathrm{SAVR}+\mathrm{CABG}$ & 91.5 & 91.7 & 90.8 & 92.1 & .727 \\
\hline SAVR + MV procedure & 89.9 & 94.3 & 83.2 & 94.1 & .026 \\
\hline \multicolumn{6}{|l|}{ Isolated SAVR } \\
\hline$\geq 70 y$ & 93.5 & 92.3 & 92.0 & 95.4 & .133 \\
\hline $60-69$ y & 98.2 & 98.9 & 97.4 & 98.5 & .484 \\
\hline $50-59$ y & 95.9 & 94.8 & 96.1 & 96.4 & .831 \\
\hline Mechanical & 95.9 & 95.3 & 95.6 & 97.3 & .376 \\
\hline Biological & 95.5 & 97.6 & 94.0 & 96.3 & .131 \\
\hline Female & 95.9 & 94.5 & 94.6 & 98.2 & .027 \\
\hline Male & 95.6 & 96.5 & 94.8 & 95.7 & .574 \\
\hline High-risk patients (LES $\geq 20$ ) & 89.0 & N/A & 90.9 & 88.1 & .797 \\
\hline Intermediate-risk patients (LES 10-20) & 94.2 & N/A & 93.3 & 94.7 & .780 \\
\hline Low-risk patients (LES <10) & 97.3 & N/A & 97.9 & 97.1 & .491 \\
\hline \multicolumn{6}{|l|}{ SAVR with $C A B G$} \\
\hline$\geq 70 y$ & 89.4 & 89.3 & 88.3 & 90.6 & .639 \\
\hline $60-69$ y & 94.1 & 93.6 & 93.7 & 94.7 & .913 \\
\hline $50-59 y$ & 96.6 & 97.2 & 97.8 & 94.1 & .647 \\
\hline Mechanical & 91.3 & 90.5 & 93.0 & 90.2 & .659 \\
\hline Biological & 91.6 & 95.6 & 89.7 & 92.6 & .185 \\
\hline Female & 91.7 & 92.1 & 93.6 & 89.2 & .432 \\
\hline Male & 91.5 & 91.6 & 89.5 & 93.2 & .215 \\
\hline High-risk patients (LES $\geq 20$ ) & 76.9 & N/A & 90.0 & 72.4 & .282 \\
\hline Intermediate-risk patients (LES 10-20) & 89.2 & N/A & 91.8 & 88.3 & .628 \\
\hline Low-risk patients $($ LES < 10) & 94.1 & N/A & 93.8 & 94.2 & .841 \\
\hline
\end{tabular}


TABLE E5. Five-year survival after primary surgical aortic valve replacement over 3 decades

\begin{tabular}{|c|c|c|c|c|c|}
\hline \multicolumn{6}{|c|}{ 5-y survival } \\
\hline & All patients & Period A 1987-1996 & Period B 1997-2006 & Period C 2007-2016 & $P$ value \\
\hline Overall cohort & 82.4 & 84.5 & 80.9 & 82.9 & .059 \\
\hline Isolated SAVR & 86.8 & 86.9 & 85.8 & 87.8 & .454 \\
\hline $\mathrm{SAVR}+\mathrm{CABG}$ & 77.5 & 79.7 & 75.3 & 78.4 & .301 \\
\hline $\mathrm{SAVR}+\mathrm{MV}$ procedure & 79.3 & 82.8 & 73.0 & 84.6 & .143 \\
\hline \multicolumn{6}{|l|}{ Isolated SAVR } \\
\hline$\geq 70 y$ & 81.2 & 79.9 & 80.3 & 82.6 & .624 \\
\hline $60-69 y$ & 89.6 & 91.4 & 87.8 & 89.8 & .471 \\
\hline $50-59 y$ & 91.4 & 86.9 & 91.3 & 94.0 & .210 \\
\hline Mechanical & 89.7 & 87.2 & 89.2 & 93.9 & .019 \\
\hline Biological & 84.0 & 85.6 & 82.9 & 84.7 & .618 \\
\hline Female & 88.8 & 86.0 & 87.3 & 92.1 & .049 \\
\hline Male & 85.5 & 87.4 & 84.6 & 85.1 & .546 \\
\hline High-risk patients (LES $\geq 20$ ) & 75.6 & N/A & 81.8 & 71.5 & .559 \\
\hline Intermediate-risk patients (LES 10-20) & 78.7 & N/A & 80.0 & 78.0 & .766 \\
\hline Low-risk patients (LES <10) & 89.1 & N/A & 89.0 & 89.2 & .928 \\
\hline \multicolumn{6}{|l|}{ SAVR with CABG } \\
\hline$\geq 70 y$ & 71.9 & 72.4 & 69.2 & 74.4 & .343 \\
\hline $60-69$ y & 84.1 & 84.1 & 84.1 & 84.1 & $>.999$ \\
\hline $50-59$ y & 90.3 & 94.4 & 88.9 & 87.4 & .596 \\
\hline Mechanical & 81.2 & 80.2 & 83.2 & 79.7 & .716 \\
\hline Biological & 75.3 & 78.3 & 71.5 & 78.1 & .097 \\
\hline Female & 80.0 & 81.3 & 80.7 & 78.2 & .813 \\
\hline Male & 76.4 & 79.0 & 72.7 & 78.5 & .120 \\
\hline High-risk patients (LES $\geq 20$ ) & 50.4 & N/A & 40.0 & 54.7 & .694 \\
\hline Intermediate-risk patients (LES 10-20) & 73.1 & N/A & 66.8 & 75.3 & .431 \\
\hline Low-risk patients $($ LES < 10) & 81.0 & N/A & 81.3 & 80.8 & .947 \\
\hline
\end{tabular}

$\overline{S A V R}$, Surgical aortic valve replacement; $C A B G$, coronary artery bypass grafting; $M V$, mitral valve; $L E S$, logistic European System for Cardiac Operative Risk Evaluation; $N / A$, not available. 